\title{
In vitro cultures of Scutellaria alpina as a source of pharmacologically active metabolites
}

\author{
Izabela Grzegorczyk-Karolak $^{1}$ - Lukasz Kuźma ${ }^{1} \cdot$ Halina Wysokińska $^{1}$
}

Received: 17 June 2015/Revised: 2 September 2015/Accepted: 17 November 2015/Published online: 10 December 2015

(C) The Author(s) 2015. This article is published with open access at Springerlink.com

\begin{abstract}
Callus, cell suspension, and shoot cultures as well as in vitro-derived plants of Scutellaria alpina grown under greenhouse (for 3 months) and field conditions (for 2 years) were established, and their flavonoid (baicalin, wogonoside, luteolin) and phenylethanoid glycoside (verbascoside) contents were determined by ultra performance liquid chromatography. The quantities of individual compounds were influenced by the type of analyzed plant material, its age, and day of culture passage. Undifferentiated callus and cell suspension cultures of S. alpina showed higher amounts of metabolites than the proliferating shoot cultures. The highest baicalin $\left(26.25 \mathrm{mg} \mathrm{g}^{-1}\right.$ dry wt) and wogonoside (15.60 $\mathrm{mg} \mathrm{g}^{-1}$ dry wt) levels were found in callus cultured for 1.5-2 years on MS agar medium supplemented with NAA $\left(0.1 \mathrm{mg} \mathrm{l}^{-1}\right)$ and TDZ $\left(0.2 \mathrm{mg} \mathrm{l}^{-1}\right)$, which were similar to these yielded by 3 -month-old and 2-year-old plant roots of S. alpina. The maximum level of verbascoside $\left(27.21 \mathrm{mg} \mathrm{g}^{-1}\right.$ dry wt) was achieved in cell suspension culture maintained for 1 year in MS liquid medium with NAA $\left(0.1 \mathrm{mg} \mathrm{l}^{-1}\right)$ and TDZ $\left(0.2 \mathrm{mg} \mathrm{l}^{-1}\right)$. The amount was found to be about 3-4fold higher than in shoots and roots of S. alpina micropropagated plants grown in field condition (7.2-9.7 $\mathrm{mg} \mathrm{g}^{-1} \mathrm{dry} \mathrm{wt}$ ). Our results suggest that in vitro cultures of $S$. alpina represent effective system for the production of the bioactive compounds with different pharmacological activity during long-term subculturing.
\end{abstract}

Communicated by M. H. Walter.

Izabela Grzegorczyk-Karolak

izabela.grzegorczyk@umed.lodz.pl

1 Department of Biology and Pharmaceutical Botany, Medical University of Łódź, ul. Muszyńskiego 1, 90-151 Łódź, Poland
Keywords Cell cultures $\cdot$ Flavonoid content $\cdot$ Scutellaria alpina $\cdot$ Shoot cultures $\cdot$ Verbascoside

\section{Introduction}

The genus Scutellaria contain over 350 species (Paton 1990) represented by perennial and annual herbs, some of which are widely used in traditional medicine especially in China, Korea, and Japan due to their anti-inflammatory, antiviral, sedative, antithrombotic, and antioxidant effects (Jiangsu New Medical College 1977). These therapeutic effects are correlated with the content of flavonoids, among which, baicalin, baicalein, and wogonoside are the major compounds. Baicalein and baicalin exhibit superior free radical scavenging and have been shown to attenuate oxidative stress in cardiomyocytes (Shao et al. 1999) and neuronal cells (Gao et al. 2001). Li et al. (2000a) report that baicalin could form a complex with a number of chemokines and block their interaction with the receptors. In addition to being an anti-inflammatory agent, the compound has also been found to inhibit HIV-1 infection of human peripheral blood mononuclear cells (Kitamura et al. 1998). Wogonoside has strong activity against lipid peroxidation and an inhibitory effect on histamine and $\operatorname{IgE}$ production (Lim 2003). It inhibits lipopolysaccharide-induced angiogenesis (Chen et al. 2009).

Besides flavones, Scutellaria plants also contain verbascoside. The phenylethanoid glycoside has been used to treat inflammation and microbial infection (Georgiev et al. 2012). The naturally occurring water-soluble phenylethanoid glycoside down-regulates $\mathrm{Ca}^{2+}$-dependent MAPK signaling in basophilic cells (Motojima et al. 2013). It appears to become involved in the inhibition of type I allergies. Recent studies have investigated the 
cytoprotective properties of verbascoside: the compound protects human cells due to the up-regulation of endogenous detoxifying system (Sgarbossa et al. 2012). Verbascoside has been reported to exhibit antiproliferative activities toward some tumor cells in vitro (Wartenberg et al. 2003), to repair DNA damage ( $\mathrm{Li}$ et al. 2000b), and to induce carcinoma cell differentiation and apoptosis by telomere-telomerase-cell cycle-dependent modulation (Zhang et al. 2002).

Production of the bioactive flavonoids and verbascoside has been well described for $S$. baicalensis and $S$. lateriflora (Yamamoto et al. 1989a; Seo et al. 1993, 1996; Islam et al. 2011; Marsh et al. 2014). However, there is little information on the accumulation of these compounds in other Scutellaria species. The present study focuses on the production of the secondary metabolites in Scutellaria alpina. S. alpina is a perennial herb distributed in Alpine districts of Europe and cultured as garden species for its attractive flowers (Yamamoto 1991). Zgórka (2006) isolated baicalin in the aerial parts of the plant. Earlier studies have also noted high verbascoside production in the roots of $S$. alpina plants cultured in vitro (Nishikawa et al. 1999).

Recently, biotechnological techniques based on in vitro cultures have been used as an alternative source to whole plant cultivation to produce valuable natural products (Zarate and Verpoorte 2007). In vitro production is not dependent on geography and seasonal variation. However, the balance between the activities of the primary and secondary metabolism in dynamic one could be largely affected by culture growth, tissue differentiation, and development of plant body (Collin 2001). Therefore, in the present study, we established biotechnological potential in vitro cultures of $S$. alpina at different stages of differentiation (callus, cell suspension, and organized shoot cultures) as well as intact plants derived from the shoot tips of aseptically germinated seedlings, and their ability to accumulate flavones and verbascoside was evaluated by UPLC quantification.

\section{Materials and methods}

\section{Plant material}

Scutellaria alpina seeds were obtained from the Botanical Garden of Institute of Ecology and Botany in Vacratot (Hungary). The seeds were surface sterilized using sodium hypochlorite $(1 \%)$ for $10 \mathrm{~min}$, and then rinsed three times in sterile distilled water. Sterilized seeds were transferred into MS (Murashige and Skoog 1962) agar (0.7\%) medium supplemented with kinetin $\left(0.02 \mathrm{mg} \mathrm{l}^{-1}\right)$ and gibberellic acid $\left(1 \mathrm{mg} \mathrm{l}^{-1}\right)$ for germination. The seeds germinated after 1 week in culture condition. The 3 -weekold seedlings provided material for in vitro cultures used in this study.

\section{Callus culture}

Scutellaria alpina callus culture was obtained from hypocotyls of 3-week-old aseptically germinated seedlings. MS agar $(0.7 \%)$ medium with $0.1 \mathrm{mg} \mathrm{l}^{-1}$ NAA ( $\alpha$-naphthaleneacetic acid) and $0.2 \mathrm{mg}^{-1} \mathrm{TDZ}$ (thidiazuron) was used for callus culture initiation and further cultivation; the calli were transferred into the same fresh medium at 2-week intervals. For subcultures, an inoculum of about $200 \mathrm{mg}$ fresh weight was transferred into glass culture tubes ( $\varnothing 25 \mathrm{~mm}$, a length of $18 \mathrm{~cm}$, purchased from SLINAP, Łódź, Poland) containing $25 \mathrm{ml}$ experimental medium. Secondary metabolite analyses were performed after 10, 20, 30, 40, 50, and 60 subcultures (about 5, 10, 14, 19, 24 , and 28 months after culture initiation).

\section{Cell suspension culture}

Cell suspension culture was obtained from hypocotylderived stable callus grown in in vitro culture for 20 subcultures. About $3 \mathrm{~g}$ of actively growing callus was transferred into 300-ml Erlenmeyer flasks containing $50 \mathrm{ml}$ of liquid MS medium supplemented with $0.1 \mathrm{mg}^{-1} \mathrm{NAA}$ and $0.2 \mathrm{mg}^{-1}$ TDZ. The cultures were maintained on a rotary shaker $(100 \mathrm{rpm})$ at intervals of 14 days. The inoculum fresh weight was about $800 \mathrm{mg}$ per flask. Secondary metabolite analyses were performed after $5,10,15$, 20,25 , and 30 subcultures $(2.5,5,7.5,10,12.5$, and 14 months after culture initiation).

\section{Growth kinetics of callus and cell suspension cultures}

In order to determine growth profiles, an inoculum of callus and cell culture material equivalent to $0.21 \pm 0.011$ and $0.81 \pm 0.10 \mathrm{~g}$ fresh weight (for callus and cell suspension growth curves, respectively) were transferred to MS medium containing supplements $\left(0.1 \mathrm{mg} \mathrm{l}^{-1}\right.$ NAA and $0.2 \mathrm{mg}^{-1} \mathrm{TDZ}$ ) and incubated in vitro under conditions described above. Growth was measured in terms of dry and fresh weights. The samples were harvested on days 5,10 , 15,20 , and 25 (for callus culture) and on $3,6,9,12,15,18$, 21 , and 24 (for cell suspension). The experiments were conducted in triplicate (three series of three culture vessel; nine samples for each time point). 


\section{Shoot culture and plant regeneration}

The shoot tips of 3-week-old aseptically germinated seedlings with one pair of leaves were used as initial explants for shoot culture. MS medium supplemented with $0.1 \mathrm{mg} \mathrm{l}^{-1}$ IAA (3-indoleacetic acid) and $0.5 \mathrm{mg} \mathrm{l}^{-1}$ BAP (6-benzylaminopurine) and solidified with $0.7 \%$ agar was used for axillary shoot multiplication. Subcultures were made at 5-week intervals using individual shoot tips as explants and number of newly formed shoots was counted. Secondary metabolite analyses were performed after 6, 16, 26, 36 subcultures $(6,18,30$, and 42 months after culture initiation).

To obtain plantlets, the shoots after six subcultures were transferred into half-strength MS (1/2 strength macronutrients) agar medium without growth regulators for rooting. After 4 weeks, the plantlets were moved to small pots containing a sterilized mixture of sand, peat, and soil $(3: 3: 4$ v/v/v) (Grzegorczyk-Karolak et al. 2013). They were grown in the greenhouse for 12 weeks. The acclimatized plants were transferred to the open field condition (Medical Plant Garden of the Department of Pharmacognosy at the Medical University of Lodz). The shoots and roots of 12-week-old plants grown in the greenhouse and 2-year-old plants at the flowering stage grown in the field were collected for secondary metabolite analysis. The plant species was identified on the basis of Flora Europaea (Tutin et al. 1972) by dr I. Grzegorczyk-Karolak. Voucher specimens were deposited in the Department of Biology and Pharmaceutical Botany, Medical University of Łódź.

\section{Culture conditions}

All cultures were kept at $26 \pm 2{ }^{\circ} \mathrm{C}$ under a photoperiod of $16 \mathrm{~h}$ light provided by cool white fluorescent lamps $\left(40 \mu \mathrm{M} \mathrm{m}^{-2} \mathrm{~s}^{-1}\right)$.

\section{Extraction and analysis of secondary metabolites}

The lyophilized plant material $(250 \mathrm{mg})$ was pre-extracted with chloroform overnight. After filtration, the remaining plant material was extracted three times with $70 \%$ methanol $(30 \mathrm{ml})$ at $15 \mathrm{~min}$ in the ultrasonic bath. The extracts were combined and evaporated under reduced pressure. The dry residue was dissolved in $2 \mathrm{ml}$ of methanol and subjected to UPLC analysis using Agilent Technologies 1290 Infinity apparatus (Agilent Technologies, USA). For separation of compounds, a Zorbax Eclipse Plus C18 column $(100 \times 3 \mathrm{~mm} ; 1.8 \mu \mathrm{m}$ Agilent Technologies) was eluted using the mobile phase consisted of $0.1 \%$ formic acid in acetonitrile (v/v) (solvent $\mathrm{A}$ ) and $0.1 \%$ formic acid in water (v/v) (solvent B). A gradient program was applied as follows: 0-15 min 20-30\% solvent A, 15.1-17 min $99 \%$ solvent A. Details of the UPLC procedure were as described previously (GrzegorczykKarolak et al. 2015a). The compounds were identified and quantified at $320 \mathrm{~nm}$. They were identified by comparison of their retention times UV spectra and mass spectra (Grzegorczyk-Karolak et al. 2013, 2015b) with those of the standard compounds. Verbascoside (Phytoplan), baicalin (Sigma-Aldrich), luteolin (Roth), and wogonoside (ChemFace) were used as standards. Chromatographic separation of extract from S. alpina cell culture is presented in Fig. 1. The quantification of compounds was calculated based on the area of separate peaks using standard calibration curves. The results were expressed as $\mathrm{mg} \mathrm{g}^{-1}$ dry weight.

\section{Statistical analysis}

The results in all experiments were performed in triplicate and presented as mean \pm standard error (SE). The significance of differences among means was calculated using
Fig. 1 Chromatographic profile of extract from $S$. alpina cell culture at day 14 of the growth cycle (passage 15). 1

Verbascoside, 2 baicalin, 3 luteolin, 4 wogonoside

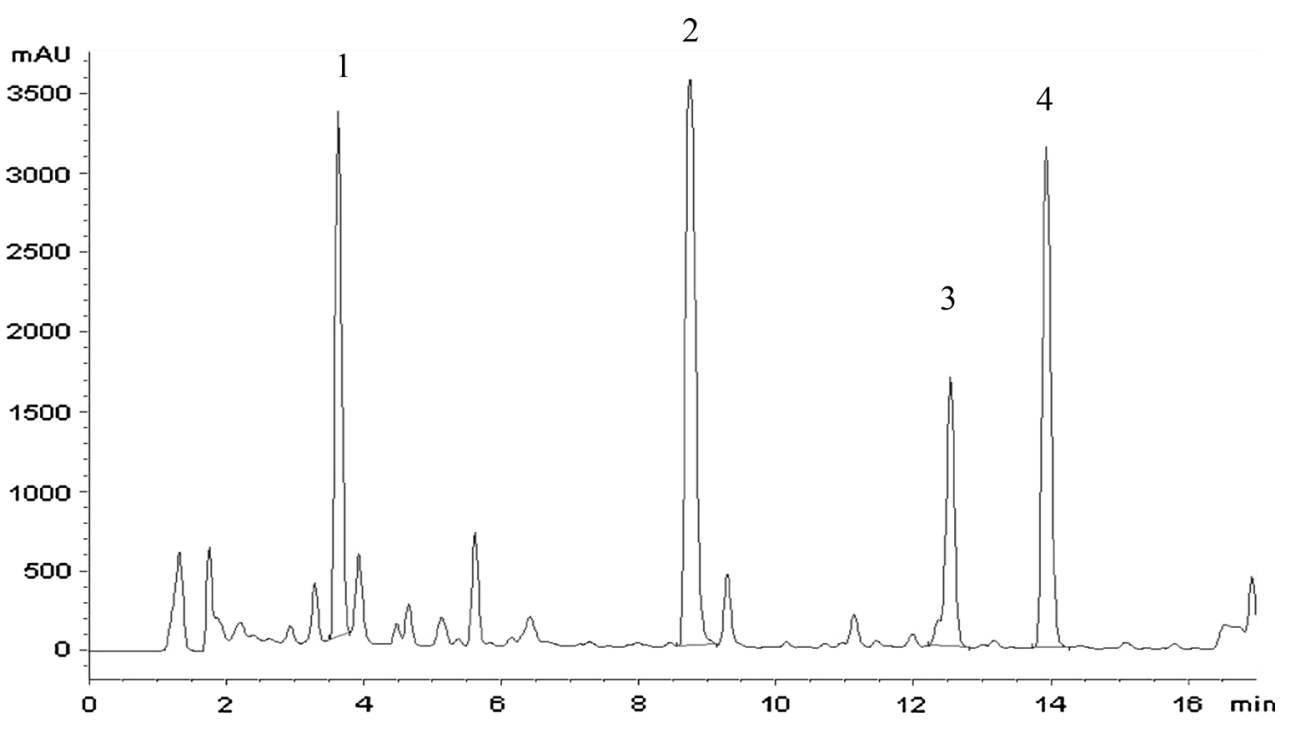


the Kruskal-Wallis test. Statistica 10.0 software was used for all calculations (Statsoft Poland). Relationships were considered significant at $p \leq 0.05$.

\section{Results}

\section{Callus and suspension culture growth characteristics}

Scutellaria alpina callus culture was initiated from hypocotyl seedlings and maintained on MS agar medium containing NAA $\left(0.1 \mathrm{mg} \mathrm{l}^{-1}\right)$ and $\operatorname{TDZ}\left(0.2 \mathrm{mg} \mathrm{l}^{-1}\right)$ by regular subcultures at 2 -week intervals. This medium was selected for callus formation according to earlier published data for S. baicalensis ( $\mathrm{Li}$ et al. 2000c) and the results of our own preliminary experiments (data not shown). The light-green callus grew vigorously as friable undifferentiated tissue throughout the experimental period. Biomass accumulation was examined at 25-day interval measuring fresh and dry weight (Fig. 2a). Callus culture was in lag phase for 5 days, then started to grow exponentially up to the 15th day, reaching a stationary phase within 15-20 days. At the time, fresh biomass $3.6 \mathrm{~g} /$ tube $(25 \mathrm{ml}$ medium) and dry biomass $0.14 \mathrm{~g} /$ tube were observed.
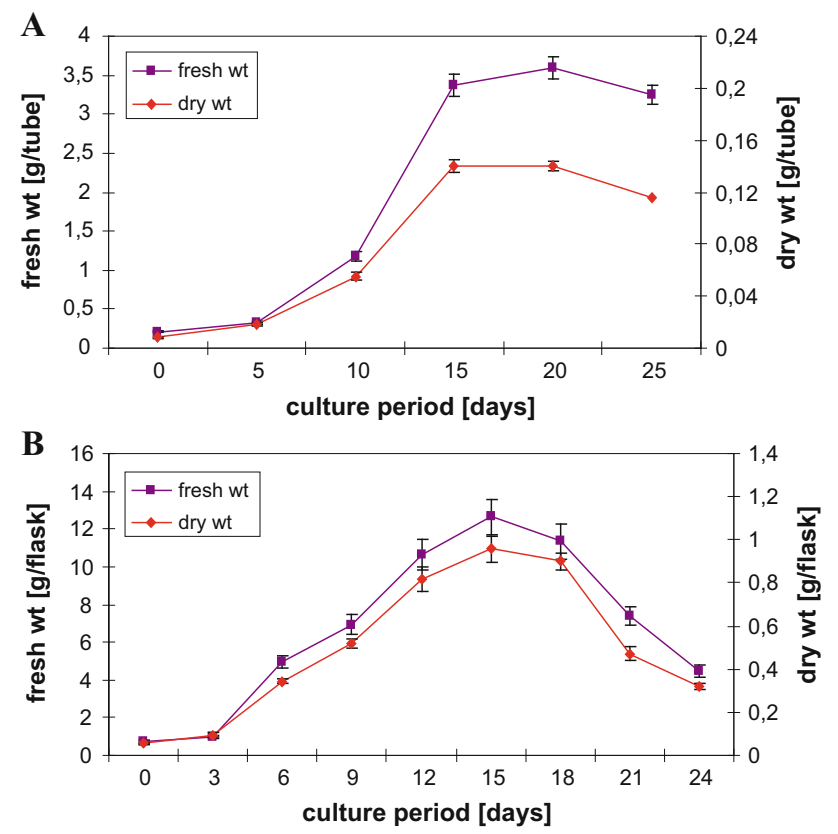

Fig. 2 Time course analysis of $S$. alpina callus (a) and cell suspension (b) culture growth. Callus was cultured in tubes containing $25 \mathrm{ml}$ of MS agar solidified medium supplemented with $0.1 \mathrm{mg}^{-1} \mathrm{NAA}$ and $0.2 \mathrm{mg}^{-1} \mathrm{TDZ}$. Cell suspension culture was maintained in 300-ml Erlenmeyer flask containing $50 \mathrm{ml}$ of MS liquid medium supplemented with $0.1 \mathrm{mg}^{-1} \mathrm{NAA}$ and $0.2 \mathrm{mg}^{-1} \mathrm{TDZ}$. The value is the average of three separate experiments for each time point $(n=9) \pm$ standard error
Later, the fresh and dry biomass began to decline, and the callus turned brown and died (Fig. 2a).

From the hypocotyl-derived callus subcultured for 20 passages, cell suspension culture of S. alpina was established. The composition of the medium was the same as that for callus culture (MS with $0.1 \mathrm{mg} \mathrm{l}^{-1} \mathrm{NAA}$ and $0.2 \mathrm{mg}^{-1} \mathrm{TDZ}$ ), but without agar. Figure $2 \mathrm{~b}$ shows a typical growth curve of cell suspension culture of $S$. alpina. The first 3 days were the lag period of growth, and then fresh and dry biomass began to increase gradually until day 15 . The stationary phase was observed from day 15 to day 18 of culture. The highest biomass of $12.6 \mathrm{~g} /$ flask $(50 \mathrm{ml}$ medium) fresh wt and $0.96 \mathrm{~g} /$ flask dry wt was achieved at 15 th day.

\section{Shoot culture and plant regeneration}

Shoot culture of S. alpina was obtained when shoot tips excised from aseptically germinated seedlings were cultured on MS agar medium supplemented with $0.1 \mathrm{mg}^{-1}$ IAA and $0.5 \mathrm{mg}^{-1}$ BAP. An average of 25 new shoots per explant was formed within 5 weeks. The shoots were taken for further multiplication or formed roots after transfer to $1 / 2 \mathrm{MS}$ medium without growth regulators. Root formation was observed within 4 weeks with $90 \%$ efficiency. The wellrooted plantlets were transferred into pots and acclimatized in the greenhouse (Grzegorczyk-Karolak et al. 2013). The survival rate of the plants was $96 \%$ after 3 months. The acclimatized plants were transferred to open field conditions.

\section{Polyphenolic compound accumulation}

Undifferentiated (callus and cell suspension) and differentiated (multiple shoots) cultures as well as shoots and roots of in vitro-derived plants of S. alpina were studied on the content of polyphenolic compounds (baicalin, wogonoside, luteolin, and verbascoside) by UPLC. The compounds were identified by comparison of the MS spectra of standards (baicalin, wogonoside, luteolin, verbascoside) and extracted sample, together with the agreement of UV spectra and retention times (UV-UPLC) (GrzegorczykKarolak et al. 2013, 2015b). Since it is known that secondary metabolite biosynthesis can be affected during long-term subculture, the contents of verbascoside, baicalin, wogonoside, and luteolin in callus, cell suspension, and shoot cultures at different passages were investigated (Fig. 3). In the shoot culture grown on MS agar medium supplemented with $0.1 \mathrm{mg}^{-1}$ IAA and $0.5 \mathrm{mg} \mathrm{l}^{-1}$ BAP over 3.5 years ( 36 passages, 5 weeks each), the values between $6.3 \pm 0.05$ and $8.1 \pm 0.09 \mathrm{mg}$ verbascoside, $4.3 \pm 0.08$ and $11.7 \pm 0.04 \mathrm{mg}$ baicalin, $1.4 \pm 0.12$ and $3.2 \pm 0.05 \mathrm{mg}$ wogonoside, and $1.9 \pm 0.05$ and $3.35 \pm 0.05 \mathrm{mg}$ luteolin per gram dry wt were measured. 

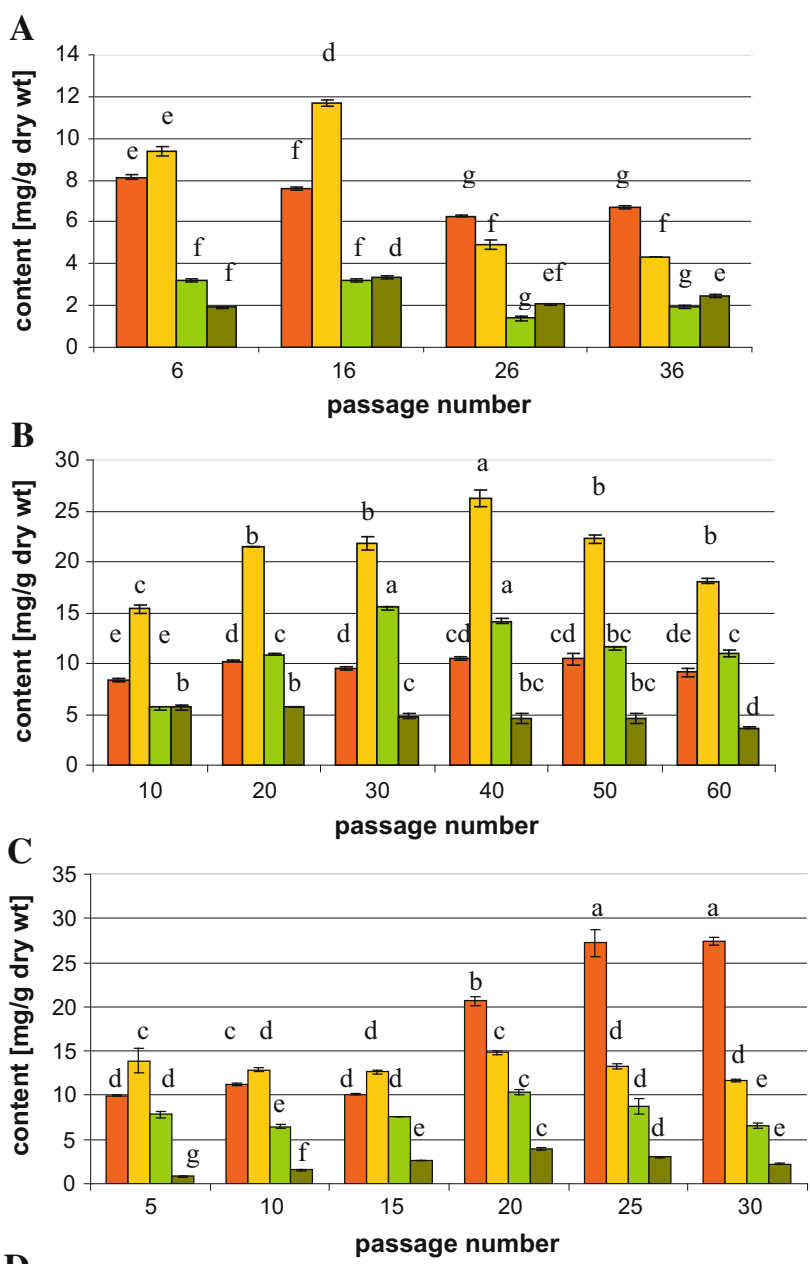

D

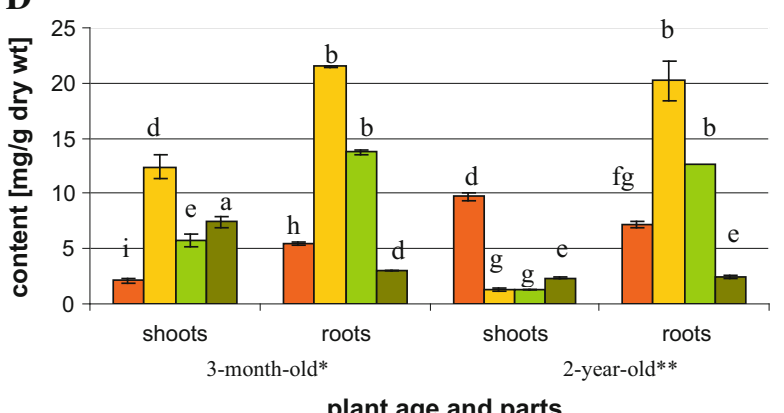

plant age and parts

$\square$ verbascoside $\square$ baicalin $\square$ wogonoside $\square$ luteolin

Fig. 3 Baicalin, wogonoside, luteolin, and verbascoside levels in $S$. alpina shoot (a), callus (b), cell suspension cultures (c), and in vitro regenerated plants (d) grown *in the greenhouse and **in the field. Means values \pm standard error obtained from three independent measurements with $n=9$. Bars with the different letters for the same metabolite are significant at $p \leq 0.05$

The differences in level of these compounds were most noticeable during the period between 16 and 26 passages (between $1 \frac{1}{2}$ and $2^{1 / 2}$ years in in vitro culture), when the total polyphenol content (calculated as the sum of baicalin, wogonoside, luteolin, and verbascoside) in shoots decreased from about 26 to $15 \mathrm{mg} \mathrm{g}^{-1}$ dry wt. Following this, the levels of secondary metabolites were relatively stable (Fig. 3a).

The ability to produce baicalin, wogonoside, luteolin, and verbascoside in S. alpina callus culture as a function of age is shown in Fig. 3b. Significantly higher amounts of metabolites were observed in older cultures (after 20 or more subcultures) in comparison with the cultures maintained for shorter period (after ten subcultures). For example, the concentration of baicalin (21.4 and $26.3 \mathrm{mg} \mathrm{g}^{-1}$ dry wt) in calli after 1 and 2 years of callus initiation was $40-70 \%$ higher than that in calli after 5 months of culture $\left(15.4 \mathrm{mg} \mathrm{g}^{-1}\right.$ dry wt) (Fig. 3b). It should be also noticed that in older cultures, smaller variations in quantities of secondary metabolites were observed. A similar tendency was found in the liquid cell suspension culture obtained from hypocotyl-derived callus (Fig. 3c). Cell culture examined here was maintained with the same concentration of growth regulators as callus culture over a period of 30 subcultures, subculturing at 14 days interval. The highest amount of various target compounds was reached in cells kept in in vitro culture during 20 and 25 passages: about a year. Following this, the quantities of baicalin, wogonoside, and luteolin slightly decreased between subcultures 25 and 30 , whereas the quantity of verbascoside remained at a stable high level (about $27 \mathrm{mg} \mathrm{g}^{-1}$ dry wt) over 30 passages (Fig. 3c).

In $S$. alpina, the accumulation of compounds in callus and suspension cultures was investigated in detail during one growth cycle, i.e., for 24 days for liquid and for 25 days for solid culture. The maximum contents of all analyzed compounds in callus culture were achieved on day 15 of cultivation. It was demonstrated that baicalin and wogonoside levels varied little during the experimental period. The contents of the compounds in callus biomass harvested at the optimal time, i.e., day 15 of the growth cycle, were about 35 and $30 \%$ higher compared to those found at the beginning of growth cycle (day 5) $(16.9 \pm 1.35$ vs. $12.6 \pm 1.21$ and $10.4 \pm 0.39$ vs. $8.2 \pm 0.4 \mathrm{mg} \mathrm{g}^{-1}$ dry wt, respectively). The increase for verbascoside was $60 \%$. Greatest variation was recorded in the concentration of luteolin; its amount measured over a 20-day growth cycle showed a 2.5 -fold difference between the lowest (day 5) and the highest (day 15) level of accumulation (Fig. 4a). A 24-day period of cell suspension culture was selected to study the polyphenol accumulation dynamics (Fig. 4b). It was demonstrated that the plant cells cultured in the liquid medium accumulated the highest amounts of baicalin, wogonoside, and verbascoside at the stationary phase, although optimal day differed for individual metabolite (Fig. 4b). The highest production of baicalin $\left(17.7 \pm 0.8 \mathrm{mg} \mathrm{g}^{-1}\right.$ dry wt) can be achieved on day 18 of the culture cycle, whereas the highest level of 

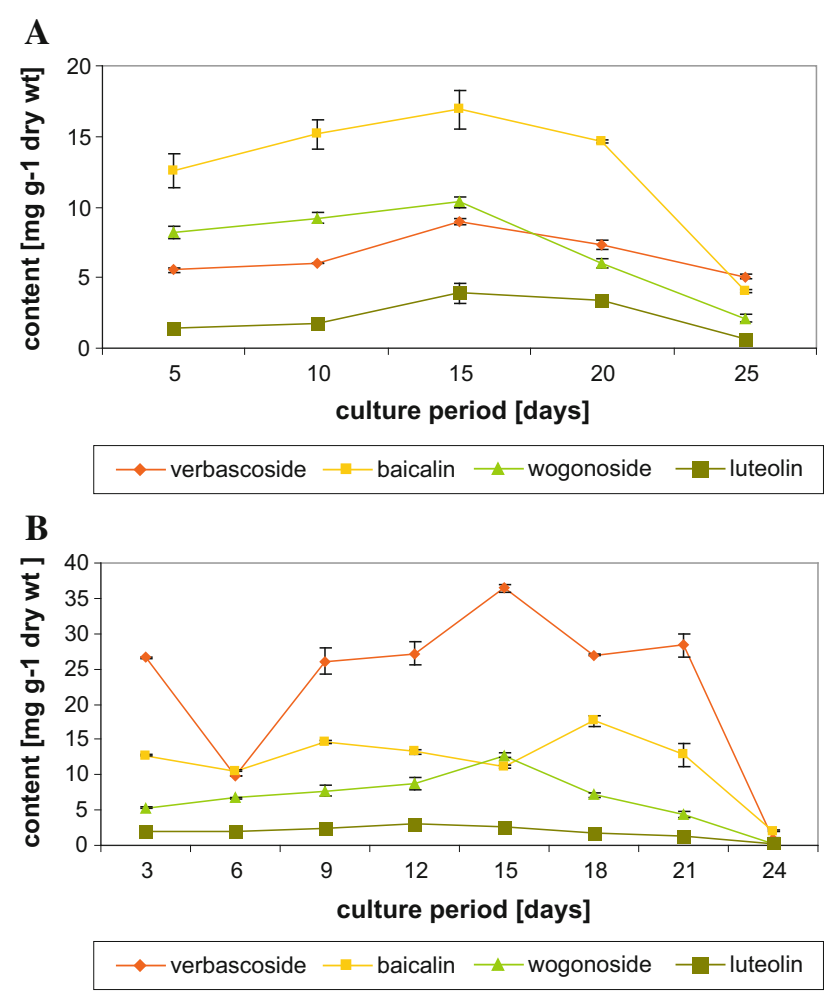

Fig. 4 Time course of baicalin, wogonoside, luteolin, and verbascoside accumulation in callus (a) and cell suspension culture (b) of $S$. alpina. The value is the average of three separate experiments for each time point $(n=9) \pm$ standard error

wogonoside $\left(12.7 \pm 0.33 \mathrm{mg} \mathrm{g}^{-1}\right.$ dry wt) was observed at day 15 . The content of verbascoside showed the largest variation during the cell culture growth cycle from the lowest concentration $9.8 \pm 0.05 \mathrm{mg} \mathrm{g}^{-1}$ dry wt on the 6th day to the highest content of $36.4 \pm 0.6 \mathrm{mg} \mathrm{g}^{-1}$ dry wt on the 15th day (Fig. 4b). On the other hand, luteolin level remained constant during the whole growth cycle (18 days).

As it is evident from Fig. 3a-c, the contents of baicalin, wogonoside, luteolin, and verbascoside in undifferentiated cultures of S. alpina were higher compared to those in organized shoot culture. The calli maintained for 1-2 years (between 30th and 50th passage, 14 days each) on MS agar medium supplemented with $0.1 \mathrm{mg} \mathrm{l}^{-1} \mathrm{NAA}$ and $0.2 \mathrm{mg} \mathrm{l}^{-1}$ TDZ produced the greatest concentrations of flavones. Luteolin levels in the calli ranged from 4.5 to $4.8 \mathrm{mg} \mathrm{g}^{-1}$ dry wt. Baicalin and wogonoside amounts in the culture varied from 21.8 to 26.3 and 11.7 to $15.6 \mathrm{mg} \mathrm{g}^{-1}$ dry wt, respectively (Fig. 3b). The levels were similar to those in roots of in vitroderived plants of $S$. alpina grown in the greenhouse for 3 months or in a field for 2 years, which accumulated 20.2 and $21.5 \mathrm{mg} \mathrm{g}^{-1}$ dry wt of baicalin and 12.7 and $13.7 \mathrm{mg} \mathrm{g}^{-1}$ dry wt of wogonoside, respectively. There was no significant difference in content of those compounds between roots of plants cultivated in the greenhouse for 3 months and plants that were cultivated for 2 years in the field (Fig. 3d). Such differences were observed between shoots of these plants. The baicalin content in shoots of younger plants was almost ten times $\left(12.4 \pm 1.02 \mathrm{mg} \mathrm{g}^{-1}\right.$ dry wt) higher than that in shoots of older plants $\left(1.29 \pm 0.08 \mathrm{mg} \mathrm{g}^{-1}\right.$ dry wt). A similar tendency was found regarding the accumulation of wogonoside ( $5.78 \pm 0.55$ vs. $1.29 \pm 0.06 \mathrm{mg} \mathrm{g}^{-1}$ dry wt).

A comparative analysis of callus culture and corresponding cell suspension showed that the latter produced approximately 2-times less baicalin, wogonoside, and luteolin (Fig. 3a, b). For example, S. alpina cells maintained as suspension liquid culture for 14 months (after 30th passage) contained $11.7 \pm 0.18 \mathrm{mg} \mathrm{g}^{-1}$ dry wt of baicalin compared to $21.8 \pm 0.63 \mathrm{mg} \mathrm{g}^{-1}$ dry wt found in callus at the same age and cultured on the solid medium of the same composition. On the other hand, among the in vitro raised tissues studied in the work, the S. alpina suspension culture was characterized by the highest content of verbascoside. The 14-month-old cell culture accumulated $27.4 \pm 0.39 \mathrm{mg}$ of the compound: i.e., three times more than those reported in the callus culture and shoots of whole plants of $S$. alpina. In this study, verbascoside content was found to increase from younger to older plants. In shoots of 3-month-old plants, verbascoside was detected at level of $2.15 \pm 0.22 \mathrm{mg} \mathrm{g}^{-1}$ dry wt, whereas in shoots of 2-year-old plants, the content was $9.71 \pm 0.36 \mathrm{mg} \mathrm{g}^{-1}$ dry wt. The same trend was observed in the roots of regenerated plants $(5.4 \pm 0.19$ vs $7.2 \pm 0.3 \mathrm{mg} \mathrm{g}^{-1}$ dry wt).

\section{Discussion}

In vitro cultures of $S$. alpina at different stages of differentiation (callus cell suspension and shoot organ culture) and in vitro-derived plants were established in order to assess their potential as producers of bioactive polyphenolic compounds. The resulting plant materials produced baicalin, wogonoside, luteolin, and verbascoside. The quantities of individual compounds varied depending on the type of analyzed plant material, its age, and day of culture passage.

It is generally accepted that undifferentiated cells, such as callus or cell suspension, are not able to produce secondary metabolites or produce them in much lower amounts than differentiated cells, specialized organ, or whole plants (Szopa et al. 2013; Sierra et al. 1991). Nevertheless, there are examples which show formation of high amounts of metabolites in undifferentiated tissues. Kiong et al. (2005) have reported that callus cultures of Centella asiatica produced 2-3 times more of the triterpenoid 
saponin madecassoside than a 4-month-old plant. Also, a suspension culture of Glechoma hederacea produced more rosmarinic acid than the roots or leaves of the plant (Doering and Petersen 2014). Similar findings are reported in our study. Callus and cell suspension cultures of S. alpina, where cells are undifferentiated, had higher ability to produce baicalin, wogonoside, verbascoside, and luteolin than culture of organized shoots. For example, the level of baicalin was $26.25 \mathrm{mg} \mathrm{g}^{-1}$ dry wt after 1.5 year in undifferentiated callus culture, but only $11.68 \mathrm{mg} \mathrm{g}^{-1}$ dry wt in shoot culture. However, it is not clear whether it is a consequence of differentiation or the influence of alternation in growth regulators in culture medium: shoots were maintained on MS medium with $0.1 \mathrm{mg} \mathrm{l}^{-1}$ IAA and $0.5 \mathrm{mg}^{-1} \mathrm{BAP}$, whereas for callus and cell cultures, MS medium with $0.1 \mathrm{mg} \mathrm{l}^{-1} \mathrm{NAA}$ and $0.2 \mathrm{mg} \mathrm{l}^{-1} \mathrm{TDZ}$ was used.

Our experiments show that metabolite contents in undifferentiated cultures of S. alpina (callus and cell suspension) were relatively low during first 5 months of cultivation, but increased during further subculture (after 1-2 years of cultivation). It is not surprising that metabolite levels over time are not constant. Reduction, loss, or fluctuations in secondary metabolite production over time have been reported in in vitro cultures of numerous plant species (Ravishankar and Venkataraman 1993). On the contrary, the accumulation of rosmarinic acid in cell and suspension culture of $S$. officinalis was constant for 1.5 year (Grzegorczyk et al. 2005). Also, Rehmannia glutinosa callus maintained the ability to produce bioactive iridoid and phenylethanoid glycosides during long-term cultivation of 4 years (Piątczak et al. 2015).

Changes in metabolite levels in callus and cell cultures of $S$. alpina were also reported based on day of culture passage. The biomass and polyphenolic accumulation profiles indicated that the best time to terminal the culture cycle was day 15-18, when the cultures were at the stationary phase. In many cell cultures, secondary metabolite production is increased by nutrient depletion and usually begins when the cultures move from exponential into stationary phase (Grzegorczyk et al. 2006; Murakami et al. 1998). The present study with $S$. alpina showed that high and stable production of analyzed compounds in callus and cell cultures could be achieved in long-term cultures (1-2year). Also, the levels of bioactive flavones, which are typical metabolites of Scutellaria genus, i.e., baicalin and wogonoside in callus, were higher when they were grown on solid agar medium than as suspension culture in the liquid medium. The most important was the finding that production of these flavones (baicalin and wogonoside) in the callus culture (26.25 and $15.6 \mathrm{mg} \mathrm{g}^{-1}$ dry wt, respectively) can be similar to that in roots of in vitro-derived plants of S. alpina and 10-20 times higher than that in aerial parts of the plants (Fig. 3d). The comparative analysis was also performed with plants after a 3-month growth period in the greenhouse and those cultivated for 2 years in the field. Similarly, high baicalin $\left(24.01 \pm 0.4 \mathrm{mg} \mathrm{g}^{-1}-\right.$ dry wt) and wogonoside (11.27 $\pm 0.5 \mathrm{mg} \mathrm{g}^{-1}$ dry wt) contents were found in roots of 2-year-old field-grown $S$. alpina plants propagated from seeds (Grzegorczyk-Karolak et al. 2015c). Therefore, callus cultures of S. alpina represent an alternative potential source for baicalin and wogonoside production, to the field-grown plants of the species. Baicalin content in S. alpina callus was several times greater than those previously reported by Nishikawa et al. (1999) for calli of several other Scutellaria species, which ranged from 0 (in $S$. pontica) to $2 \mathrm{mg} \mathrm{g}^{-1}$ dry wt (in $S$. indica). However, baicalin concentration in S. alpina callus culture was lower than that reported by Yamamoto et al. (1989a) for S. baicalensis callus (4 \%). Wogonoside content was found to be three times higher in callus cultures of S. alpina than in the calli of seven other Scutellaria species (Nishikawa et al. 1999) and similar to that detected in S. baicalensis callus culture (Yamamoto et al. 1989a).

Undifferentiated cultures of S. alpina, especially cell suspension, represent also valuable sources for the production of verbascoside. The phenylethanoid glycoside content in cell suspension kept in in vitro culture for more than 1 year (25 passages at 14-day-intervals) was $27.4 \mathrm{mg} \mathrm{g}^{-1}$ dry wt, when cells after 14 days of culture were analyzed and increased to $36 \mathrm{mg} \mathrm{g}^{-1}$ dry wt (720 $\mathrm{mg}^{-1}$ culture) on the 15 th day of the growth cycle (Fig. 4b) The value was comparable to that observed in the callus of $S$. iyoensis (about $40 \mathrm{mg} \mathrm{g}^{-1}$ dry wt), but higher than the values observed in other Scutellaria species (about 4-25 $\mathrm{mg} \mathrm{g}^{-1}$ dry wt) (Nishikawa et al. 1999). The verbascoside is not unique for Scutellaria species; it is also produced by many other plant species. It is also known that in vitro conditions promote the accumulation of the compound. For example, callus culture of Buddleja cordata produced $86 \mathrm{mg} \mathrm{g}^{-1}$ dry wt of verbascoside, compared to 10 and $68 \mathrm{mg} \mathrm{g}^{-1}$ dry wt in the leaves and roots of the wild plants, respectively (Estrada-Zúñiga et al. 2009). A similar tendency was observed in the present study with $S$. alpina, where verbascoside level in the suspension cell culture was 2-5 times higher than in roots of the plants (Fig. 3c, d).

\section{Conclusions}

In the present study, a comparison of baicalin, wogonoside, luteolin, and verbascoside production in different in vitro culture systems (callus, cell suspension, shoot cultures) and in vitro-derived plants) of S. alpina at various culture age was performed. The results indicate that it is possible to maintain the high level production of the bioactive 
compounds for a long period of time using in vitro systems. Among these systems that were tested in the current study, undifferentiated hypocotyl-derived callus of S. alpina was characterized for the highest production of baicalin and wogonoside. Their levels were comparable with those found in roots of whole plants. On the other hand, suspension culture initiated from the callus and subcultured more than 20 passages in liquid MS medium containing with $0.1 \mathrm{mg} \mathrm{l}^{-1} \mathrm{NAA}$ and $0.2 \mathrm{mg} \mathrm{l}^{-1} \mathrm{TDZ}$ produced large quantities of verbascoside, which were higher than that found in roots and shoots of S. alpina plants. High levels of baicalin, wogonoside, and verbascoside in in vitro cultures of the plant can be achieved within short time (14 days). Thus, the undifferentiated cultures of S. alpina represent promising system for the production of these bioactive metabolites with different pharmacological activities. Productivity of the cultures might be further optimized, for example, by using of biotic and abiotic elicitors. Elicitation to enhance baicalin, wogonoside, verbascoside production has been successful in several cases (Kuzovkina et al. 2005; Yamamoto et al. 1989b).

Author contribution statement I. Grzegorczyk-Karolak obtained in vitro cultures, conducted the in vitro research, regenerated plants, prepared samples for UPLC analysis, analyzed the data, and described results. Ł. Kuźma performed UPLC analysis. H. Wysokińska was responsible for verification of the paper.

Open Access This article is distributed under the terms of the Creative Commons Attribution 4.0 International License (http://crea tivecommons.org/licenses/by/4.0/), which permits unrestricted use, distribution, and reproduction in any medium, provided you give appropriate credit to the original author(s) and the source, provide a link to the Creative Commons license, and indicate if changes were made.

\section{References}

Chen Y, Lu N, Ling Y, Gao Y, Wang L, Sun Y, Qi Q, Feng F, Liu W, You Q, Kim EH (2009) Anti-inflammatory effects of Scutellaria baicalensis extract via suppression of immune modulators and MAP kinase signaling molecules. J Ethnopharmacol 126:320-331. doi:10.1016/j.jep.2009.08.027

Collin HA (2001) Secondary product formation in plant tissue cultures. Plant Growth Regul 34:119-134. doi:10.1023/A: 1013374417961

Doering AS, Petersen M (2014) Production of caffeic, chlorogenic and rosmarinic acids in plants and suspension cultures of Glechoma hederacea. Phytochem Lett 10:111-117. doi:10.1016/ j.phytol.2014.05.012

Estrada-Zúniga ME, Cruz-Sosa F, Rodríguez-Monroy M, Verde-Calvo JR, Vernon-Carter EJ (2009) Phenylpropanoid production in callus and cell suspension cultures of Buddleja cordata Kunth. Plant Cell Tiss Organ Cult 97:39-47. doi:10.1007/s11240-009-9496-Z

Gao Z, Huang K, Xu H (2001) Protective effects of flavonoids in the roots of Scutellaria baicalensis Georgi against hydrogen peroxide-induced oxidative stress in HS-SY5Y cells. Pharmacol Res 43:173-178. doi:10.1006/phrs.2000.0761

Georgiev M, Pastore S, Lulli D, Alipieva K, Kostyuk V, Potapovich A, Panetta M, Korkina L (2012) Verbascum xanthophoeniceumderived phenylethanoid glycosides are potent inhibitors of inflammatory chemokines in dormant and interferon-gamma stimulated human keratinocytes. J Ethnopharmacol 144:754-760. doi:10.1016/j.jep.2012.10.035

Grzegorczyk I, Bilichowski I, Mikiciuk-Olasik E, Wysokińska H (2005) In vitro cultures of Salvia officinalis L. as a source of antioxidant compounds. Acta Soc Bot Pol 74:17-21. doi:10. 5586/asbp.2005.003

Grzegorczyk I, Królicka A, Wysokinska H (2006) Establishment of Salvia officinalis L. hairy root cultures for the production of rosmarinic acid. Z Naturforsch C 61:351-356

Grzegorczyk-Karolak I, Kuźma Ł, Wysokińska H (2013) The use of long-term Scutellaria altissima callus cultures for shoot regeneration, production of bioactive metabolites and micropropagation. J Med Plants Res 7:3003-3313. doi:10.5897/JMPR2013. 5226

Grzegorczyk-Karolak I, Kuźma Ł, Wysokińska H (2015a) The effect of cytokinins on shoot proliferation, secondary metabolite production and antioxidant potential in shoot cultures of Scutellaria alpina. Plant Cell Tiss Organ Cult 122:699-708. doi:10.1007/s11240-015-0804-5

Grzegorczyk-Karolak I, Kuźma Ł, Wysokińska H (2015b) Study on the chemical composition and antioxidant activity of extracts from shoot culture and regenerated plants of Scutellaria altissima L. Acta Physiol Plant 37:1736-1744. doi:10.1007/ s11738-014-1736-0

Grzegorczyk-Karolak I, Wysokińska H, Olas B (2015c) Studies on the antioxidant properties of extracts from the roots and shoots of two Scutellaria species in human blood plasma. Acta Biochim Pol 62:253-258. doi:10.18388/abp.2014_944

Islam MN, Downey F, Ng CKY (2011) Comparative analysis of bioactive phytochemicals from Scutellaria baicalensis, Scutellaria lateriflora, Scutellaria racemosa, Scutellaria tomentosa and Scutellaria wrightii by LC-DAD-MS. Metabolomics 7:446-453. doi:10.1007/s11306-010-0269-9

Jiangsu New Medical College (1977) Dictionary of Chinese materia medical. Science and Technology Press of Shanghai, ShangHai (in Chinese)

Kiong ALP, Mahmood M, Fadzillah M, Daud SK (2005) Effect of precursor supplementation on the production of triterpenes by Centella asiatica callus cultures. Pak J Biol Sci 8:1160-1169. doi:10.3923/pjbs.2005.1160.1169

Kitamura K, Honda M, Yoshizaki H, Yamamoto S, Nakane H, Fukushima M, Ono K, Tokunaga T (1998) Baicalin, an inhibitor of HIV-1 production in vitro. Antivir Res 37:131-140. doi:10. 1016/S0166-3542(97)00069-7

Kuzovkina IN, Guseva AV, Kovacs D, Szoke E, Vdovitchenko I (2005) Flavones in genetically transformed Scutellaria baicalensis roots and induction of their synthesis by elicitation with methyl jasmonate. Russ J Plant Physiol 52:177-182. doi:10. 1007/s11183-005-0012-y

Li BQ, Fu T, Gong WH, Dunlop N, Kung HF, Yan YD, Kang J, Wang JM (2000a) The flavonoid baicalin exhibits anti-inflammatory activity by binding to chemokines. Immunopharmacology 49:295-306. doi:10.1016/S0162-3109(00)00244-7

Li YM, Han ZH, Jiang SH, Jiang Y, Yao SD, Zhu DY (2000b) Fast repairing of oxidized $\mathrm{OH}$ radical adducts of dAMP and dGMP by phenylethanoid glycosides from Scrophularia ningpoensis Hemsl. Acta Pharmacol Sin 21:1125-1129

Li H, Murch SJ, Saxena PK (2000c) Thidiazuron-induced de novo shoot organogenesis on seedlings, etiolated hypocotyls and stem 
segments of Huang-qin. Plant Cell Tiss Organ Cult 62:169-173. doi:10.1023/A:1006491408762

Lim BO (2003) Effects of wogonin, wogonoside, and 3,5,7,2',6'pentahydroxy-flavone on chemical mediator production in peritoneal exduate cells and immunoglobulin $\mathrm{E}$ of rat mesenteric lymph node lymphocytes. J Ethnopharmacol 84:23-29

Marsh Z, Yang T, Nopo-Olazabal L, Wu S, Ingle T, Joshee N, Medina-Bolivar F (2014) Effect of light, methyl jasmonate and cyclodextrin on production of polyphenolic compounds in hairy root cultures of Scutellaria lateriflora. Phytochemistry 107:50-60. doi:10.1016/j.phytochem.2014.08.020

Motojima H, Villareal MO, Ijima R, Han J, Isoda H (2013) Acteoside inhibits type allergy through the down-regulation of $\mathrm{Ca} / \mathrm{NFAT}$ and JNK MAPK signaling pathway in basophilic cells. J Nat Med 67:790-798. doi:10.1007/s11418-013-0753-4

Murakami Y, Omoto T, Asai I, Shimomura K, Yoshihira K, Ishimaru K (1998) Rosmarinic acid and related phenolics in transformed root cultures of Hyssopus officinalis. Plant Cell Tiss Organ Cult 53:75-78. doi:10.1023/A:1006007707722

Murashige T, Skoog F (1962) A revised medium for rapid growth and bioassays with tobacco tissue cultures. Physiol Plant 15:473-497. doi:10.1111/j.1399-3054.1962.tb08052.x

Nishikawa K, Furukawa H, Fujioka T, Fujii H, Mihashi K, Shimomura K, Ishimaru K (1999) Phenolics in tissue cultures of Scutellaria. Nat Med 53:209-213

Paton A (1990) A global taxonomic investigation of Scutellaria. Kew Bull 45(3):399-450

Piątczak E, Kuźma Ł, Sitarek P, Wysokińska H (2015) Shoot organogenesis, molecular analysis and secondary metabolite production of micropropagated Rehmannia glutinosa Libosch. Plant Cell Tiss Org Cult 120:539-549. doi:10.1007/s11240-0140620-3

Ravishankar GA, Venkataraman LV (1993) Role of plant cell culture in food biotechnology: current trends, limitations and future prospects. In: Prakash J, Pierik RLM (eds) Plant biotechnology: commercial prospects and problems. Oxford IBH Press, New Delhi, pp 255-274

Seo WT, Park YH, Choe TB (1993) Identification and production of flavonoids in a cell-suspension culture of Scutellaria baicalensis Georgi. Plant Cell Rep 12:414-417. doi:10.1007/BF00234703

Seo WT, Park YH, Choe TB (1996) An optimized of flavonoid production from the suspension culture of Scutellaria baicalensis Georgi. Cells J Microbiol Biotechnol 6:347-351

Sgarbossa A, Dal Bosco M, Pressi G, Cuzzocrea S, Dal Toso R, Menegazzi M (2012) Phenylethanoid glycosides from plant cell cultures induce heme oxygenase 1 gene expression in a human keratinocyte cell line by affecting the balance of NRF2 and
BACH1 transcription factors. Chem Biol Interact 199:87-95. doi:10.1016/j.cbi.2012.06.006

Shao ZH, Li CQ, Hoek TLV, Becker LB, Schumacker PT, Wu JA, Attele AS, Yuan CS (1999) Extract from Scutellaria baicalensis Georgi attenuates oxidant stress in cardiomyocytes. J Mol Cell Cardiol 31:1885-1895. doi:10.1006/jmcc.1999.1021

Sierra MI, van der Heijden R, Schripsema J, Verpoorte R (1991) Alkaloid production in relation to differentiation in cell and tissue culture of Tabernaemontana pandacaqui. Planta Med 57:543-547. doi:10.1055/s-2006-960202

Szopa A, Ekiert H, Muszyńska B (2013) Accumulation of hydroxybenzoic acids and other biologically active phenolic acids in shoot and callus cultures of Aronia melanocarpa (Michx.) Elliott (black chokeberry). Plant Cell Tiss Org Cult 113:323-329. doi:10.1007/s11240-012-0272-0

Tutin T, Heywood H, Burges A, Valentine D (eds) (1972) Flora Europaea, vol 3. Cambridge University Press, Cambridge

Wartenberg M, Budde P, de Marees PM, Grunheck F, Tsang SY, Huang Y, Chen ZY, Hescheler J, Sauer H (2003) Inhibition of tumor-induced angiogenesis and matrix-metalloproteinase expression in confrontation culture of embryoid bodies and tumor spheroids by plant ingredients used in traditional Chinese medicine. Lab Invest 83:87-98. doi:10.1097/01.LAB. $0000049348.51663 .2 \mathrm{~F}$

Yamamoto H (1991) Scutellaria baicalensis Georgi: In vitro culture and the production of flavonoids. In: Bajaj YPS (ed) Biotechnology in agriculture and forestry. Medicinal and aromatic pants III. Springer, Berlin, pp 398-418

Yamamoto H, Sano T, Tomimori T (1989a) Growth and flavonoid formation of Scutellaria baicalensis callus culture in liquid medium. Shoyakugaku Zasshi 43:87-92

Yamamoto H, Sano T, Takeuchi S, Tanaka M, Tomimori T (1989b) Flavonoid production by two-stage culture and differentiated roots of Scutellaria baicalensis callus in liquid medium. Shoyagaku Zasshi 43:188-191

Zarate R, Verpoorte R (2007) Strategies for the genetic modification of the medicinal plant Catharanthus roseus (L.) G. Don. Phytochem Rev 6:475-491. doi:10.1007/s11101-006-9020-6

Zgórka G (2006) Retention behavior of silica-bonded and novel polymeric reversed-phase sorbents in studies on flavones as chemotaxonomic markers of Scutellaria L. genus. J Chromatogr A 1120:230-236. doi:10.1016/j.chroma.2005.11.109

Zhang F, Jia Z, Deng Z, Wei Y, Zheng R, Yu L (2002) In vitro modulation of telomerase activity, telomere length and cell cycle in MKN45 cells by verbascoside. Planta Med 68:115-118. doi:10.1055/s-2002-20255 